\title{
Effect of simulated microgravity on metabolism of HGC-27 gastric cancer cells
}

\author{
ZHENG-YANG CHEN ${ }^{1}$, NAN JIANG ${ }^{1,2}$, SONG GUO ${ }^{1,2}$, BIN-BIN LI $^{2,3}$, JIA-QI YANG ${ }^{1,2}$, \\ SHAO-BIN CHAI ${ }^{2}$, HONG-FENG YAN ${ }^{2}$, PEI-MING SUN ${ }^{2}$, TAO ZHANG $^{2}$, \\ HONG-WEI SUN ${ }^{2}$, HE-MING YANG ${ }^{2}$, JIN-LIAN ZHOU ${ }^{4}$ and YAN CUI ${ }^{2}$
}

\begin{abstract}
${ }^{1}$ Department of General Surgery, The People's Liberation Army 306th Hospital of Peking University Teaching Hospital; ${ }^{2}$ Department of General Surgery, The People's Liberation Army 306th Hospital; ${ }^{3}$ Department of General Surgery, The People's Liberation Army 306th Clinical Hospital of Anhui Medical University; ${ }^{4}$ Department of Pathology,
\end{abstract}

The People's Liberation Army 306th Hospital, Beijing 100101, P.R. China

Received August 10, 2019; Accepted December 12, 2019

DOI: $10.3892 / \mathrm{ol} .2020 .11451$

\begin{abstract}
The understanding into the pathogenesis and treatment of gastric cancer has improved in recent years; however, a number of limitations have delayed the development of effective treatment. Cancer cells can undergo glycolysis and inhibit oxidative phosphorylation in the presence of oxygen (Warburg effect). Previous studies have demonstrated that a rotary cell culture system (RCCS) can induce glycolytic metabolism. In addition, the potential of regulating cancer cells by targeting their metabolites has led to the rapid development of metabolomics. In the present study, human HGC-27 gastric cancer cells were cultured in a RCCS bioreactor, simulating weightlessness. Subsequently, liquid chromatography-mass spectrometry was used to examine the effects of simulated microgravity (SMG) on the metabolism of HGC-27 cells. A total of 67 differentially regulated metabolites were identified, including upregulated and downregulated metabolites. Compared with the normal gravity group, phosphatidyl ethanolamine, phosphatidyl choline, arachidonic acid and sphinganine were significantly upregulated in SMG conditions, whereas sphingomyelin, phosphatidyl serine, phosphatidic acid, L-proline, creatine, pantothenic acid, oxidized glutathione, adenosine diphosphate and adenosine triphosphate were significantly downregulated.
\end{abstract}

Correspondence to: Professor Yan Cui, Department of General Surgery, The People's Liberation Army 306th Hospital, 9 Anxiang Beili Street, Beijing 100101, P.R. China

E-mail: dryancui@163.com

Abbreviations: RCCS, rotary cell culture system; LC-MS, liquid chromatography-mass spectrometry; SMG, simulated microgravity; NG, normal gravity; PE, phosphatidyl ethanolamine; PC, phosphatidyl choline; SM, sphingomyelin; PS, phosphatidyl serine; PA, phosphatidic acid; ECM, extracellular matrix; Cer, ceramide; Sph, sphingosine; PLD2, phospholipase D2; MMP, matrix metalloproteinase; FOXO, forkhead box $\mathrm{O}$

Key words: HGC-27, SMG, RCCS, metabolism, PE, PC, PS, PA, SM
The Human Metabolome Database compound analysis revealed that lipids and lipid-like metabolites were primarily affected in an SMG environment in the present study. Overall, the findings of the present study may aid our understanding of gastric cancer by identifying the underlying mechanisms of metabolism of the disease under SMG.

\section{Introduction}

Studies conducted in real and simulated microgravity (SMG) have demonstrated that the physiological functions of living organisms undergo substantial changes in different gravitational conditions $(1,2)$. These changes may have adverse effects, including degenerative changes to bone and muscle, cephalic fluid shifts and electrolyte disturbances, and dysfunction of the immune and cardiovascular system $(3,4)$. Based on these studies, the influence of real and SMG on human macroscopic tissue is relatively clear; however, the influence of these conditions on cells, especially cancer cells, requires further investigation.

The effect of real and SMG on different cancer cells has been previously studied (5-10) and alterations primiarly involved the morphological structure and physiological function. For example, compared with the 2D monolayer structure of cancer cells under normal gravity (NG), cells are more rounded and form complex 3D spheroid structures under SMG (5-7). Furthermore, $\mathrm{G}_{2} / \mathrm{M}$ and $\mathrm{G}_{2}+\mathrm{M}$ phases are key mitotic check points, which are increased under SMG (8) and decreased proliferation and increaseed apoptosis are also observed under decreased SMG $(9,10)$.

The influence of metabolism on cancer cells, which functions in the synthesis of various cell substances such as cell membrane, is of interest in the field of cancer. Under physiological conditions, oxidative phosphorylation is the primary process that generates ATP and glycolysis is dominant only when oxygen is low; however, the opposite is observed in tumor cells $(11,12)$. This ability of tumor cells to undergo glycolysis, even under aerobic conditions, is referred to as the Warburg effect (11), and the metabolic reprogramming of several tumor characteristics involved has been previously investigated, 
including increased ATP synthesis and uncontrolled tumor growth (13). Previous studies have demonstrated that the levels of lactic acid were increased and glucose levels decreased in gastric cancer tissues compared with the control group $(14,15)$. The high levels of lactate may be due to the Warburg effect (11), whereas the low glucose levels may be due to the elevated fructose-6-phosphokinase activity (16), high levels of glucose transporters (17) and increased type II hexokinase activity (18) in gastric cancer tissues. High activity levels of pyruvate kinase and lactate dehydrogenase are associated with cancer proliferation and poor prognosis $(19,20)$, whereas their downregulation in vitro can impair tumor invasion $(21,22)$. Based on these reports, several studies have investigated the influence of normal gravity on physiology and metabolism of cancer (23-25); however, the effect of gravity metabolism on cells, especially gastric cancer cells, is poorly understood.

Previous studies investigating MDA-MB-231 and MCF-7 breast cancer cells have reported changes in energy metabolism and increases in intracellular lactic acid and lactate dehydrogenase activity (26). Metabolomic analysis revealed several metabolic pathways affected and a number of pathways involved in glycometabolism were significantly influenced under SMG, including glycolysis, Kreb's cycle, the pentose phosphate pathway, and the glycerol-phosphate and the malate-aspartate shuttles. The following results were observed: The glycolysis pathway was stimulated by increased levels of glucose-6-phosphate and other glycolytic precursors, such as 3-phosphoglyceraldehyde and 1,3-diphosphoglyceric acid; the Kreb's cycle was activated by the accumulation of acetyl-CoA and the content of acyl-carnitine was decreased under SMG, reflected by increased acyl-CoA levels, which suggests that the $\beta$-oxidation pathway was decreased (27). Thus, to demonstrate the effects of SMG on the metabolism of HGC-27 gastric cancer cells in the present study, liquid chromatography-mass spectrometry (LC-MS) was used.

The present study aimed to improve the understanding of the physiology and pathology of gastric cancer cells under SMG. The metabolomics analysis of HGC-27 cells under SMG may promote further understanding of the regularity of tumor occurrence and the development and changes in physiological function, to provide a novel therapeutic strategy for gastric cancer.

\section{Materials and methods}

Cell culture. The gastric cancer cell line HGC-27 was purchased from the BeNa Culture Collection. Cells were cultured in RPMI 1640 medium and supplemented with $10 \%$ fetal bovine serum (both Thermo Fisher Scientific, Inc), 100 units $/ \mathrm{ml}$ penicillin and $100 \mathrm{mg} / \mathrm{ml}$ streptomycin (Gibco; Thermo Fisher Scientific, Inc) and were incubated at $37^{\circ} \mathrm{C}$ with $5 \% \mathrm{CO}_{2}$. The medium was changed three times a week.

Microgravity simulation. The RCCS bioreactor (Synthecon, Inc.) was developed by the National Aeronautics and Space Administration to simulate the effects of microgravity. A total of 12 bioreactors were used (total volume, $55 \mathrm{ml}$ ), each equipped with a gas-exchange membrane and incubated at $37^{\circ} \mathrm{C}$ with $5 \% \mathrm{CO}_{2}$. The bottom of the RCCS bioreactor was designed with a silicone membrane and prevented the formation of bubbles (28). Cells in the RCCS bioreactor were grown on cytodex-3 microcarrier beads (Sigma-Alrich; Merck $\mathrm{KGaA}$ ) to provide a solid support pretreated with phosphate buffered saline (PBS) and 75\% ethanol, and stored at $4{ }^{\circ} \mathrm{C}$. After washing cytodex-3 microcarrier beads three times with PBS, the beads were added to the rotating culture vessel. Subsequently, 7x $10^{6}$ HGC-27 cells with $250 \mathrm{mg}$ cytodex-3 microcarrier beads were seeded into a $55 \mathrm{ml}$ RCCS bioreactor containing $500 \mathrm{ml}$ of RPMI-1640 complete medium (Gibco; Thermo Fisher Scientific, Inc.), and all air bubbles were removed using a $5 \mathrm{ml}$ syringe. The rotational speed of the high aspect ratio vessel was $0.01 \mathrm{x}$ g. Control groups (NG) of $1 \mathrm{~g}$ static cultures were stored in the same incubator at $37^{\circ} \mathrm{C}$ with $5 \% \mathrm{CO}_{2}$. Both groups were cultured in the RCCS bioreactor for 1 and 3 days, respectively.

Sample preparation and treatment. The cell-microcarrier complexes were washed with PBS three times. A total of $4 \mathrm{ml}$ Trypsin $(0.25 \%$ EDTA $)$ was added at $37^{\circ} \mathrm{C}$ for $10 \mathrm{~min}$ and the cells were dislodged by intermittently tapping the flask against a hard surface. This reaction was terminated by adding $500 \mathrm{ml}$ of RPMI-1640 complete medium followed by centrifugation at $167.7 \mathrm{x} \mathrm{g}$ for $5 \mathrm{~min}$ at $37^{\circ} \mathrm{C}$. The suspension was obtained by filtering the mixture of cells and microcarriers with $70 \mu \mathrm{m}$ cell sieves. The control group was washed twice using PBS, with the addition of 2-3 $\mathrm{ml} 0.25 \%$ Trypsin-EDTA Solution (Gibco; Thermo Fisher Scientific, Inc.) at $37^{\circ} \mathrm{C}$ for $5 \mathrm{~min}$. The supernatant was discarded following centrifugation at $167.7 \mathrm{x}$ g for 5 min at $37^{\circ} \mathrm{C}$. Cells collected from NG and SMG were stored at $-80^{\circ} \mathrm{C}$ for $\sim 1$ week, prior to subsequent experimentation.

A total of $7 \times 10^{6} \mathrm{HGC}-27 \mathrm{NG}$ and SMG cells were added to $400 \mu \mathrm{l}$ cold methanol and the cell pellet was dislodged using a high flux tissue crusher (MP Biomedicals Co., Ltd.) at $4^{\circ} \mathrm{C}$. Subsequently, $100 \mu \mathrm{l}$ of distilled water was added and ultrasonic extraction (Ningbo Xinzhi Biotechnology Co., Ltd.) was performed on ice three times (10 min each time).

Analysis of metabolites using LC-MS. LC-MS was performed using a $100 \times 2.1 \mathrm{~mm}^{2}$ Acquity $1.7 \mu \mathrm{m} \mathrm{C} 18$ column and a ACQUITY Ultra High-Performance Liquid Chromatography system (both Waters Corporation). The following conditions were used; Ionization mode, positive/negative; nitrogen gas temperature, $500^{\circ} \mathrm{C}$; nebulizer pressure, $50 \mathrm{psi}$ and flow rate, $0.40 \mathrm{ml} / \mathrm{min}$. Each sample was analyzed six times and the scanning range of mass spectrometry was $50-1,000 \mathrm{~m} / \mathrm{z}$ and the resolution was $30,000 \mathrm{dpi}$.

Data processing. MS data matrices were obtained using Progenesis QI software (version 2.0; Waters Corporation). The data matrices were imported into SIMCA-P+ software (version 14.0; Sartorius AG) and unsupervised principal component analysis was used to observe the overall distribution among samples and the degree of dispersion between groups and supervised partial least square discriminant analysis (PLS-DA) was used to distinguish the overall differences of metabolic profiles among groups. For PLS-DA scores, a variable importance (VIP) value $>1$ was considered to indicate a statistically significant difference, whereas R2Y and Q2 $>0.5$ were considered to indicate a strong prediction capability. The Human Metabolme (HMDB; http://www.hmdb.ca) and 

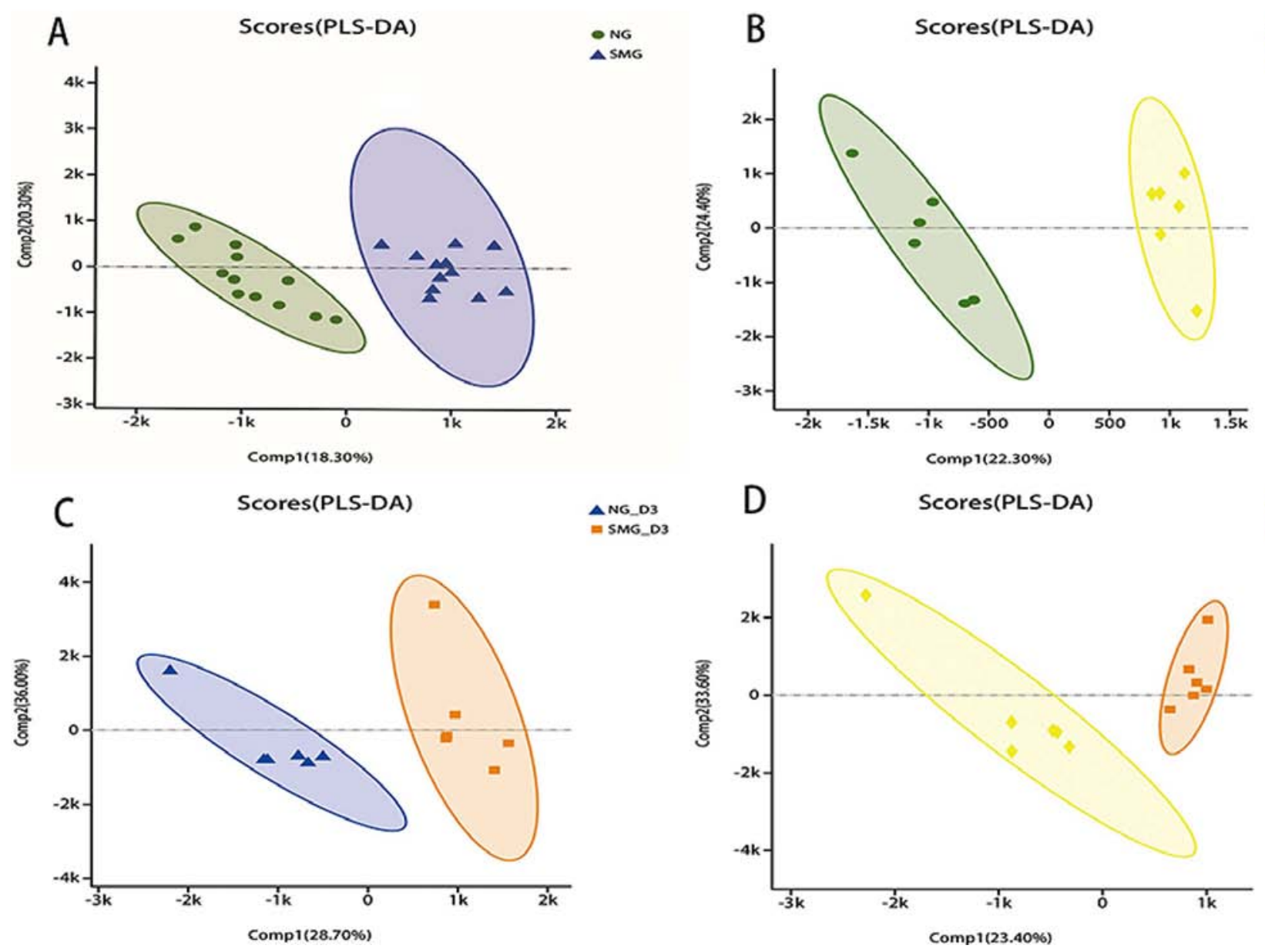

Figure 1. Metabolite-concentration distribution in HGC-27 gastric cancer cells under NG and SMG using PLS-DA. (A) Total NG for 1 and 3 days vs. total SMG for 1 and 3 days. (B) NG for 1 day vs. SMG for 1 day. (C) NG for 3 days vs. SMG for 3 days. (D) SMG for 1 day vs. SMG for 3 days. PLS-DA, partial least squares discriminate analysis; NG, normal gravity; SMG, simulated microgravity; D1, 1 day duration; D3, 3 day duration; Comp, component.

the Kyoto Encyclopedia of Genes and Genomes (KEGG; https://www.kegg.jp) databases were used to identify potential metabolites.

Statistical analysis. Statistical analysis was performed using SPSS software version 21.0 (IBM Corp.). Data are expressed as the mean \pm standard deviation for continuous variables and were analyzed using an independent sample t-test or one-way ANOVA, followed by Tukey's post-hoc test. $\mathrm{P}<0.05$ was considered to indicate a statistically significant difference. All experiments were performed in triplicate.

\section{Results}

Metabolic alterations of HGC-27 cells under NG and SMG. The PLS-DA scores in HGC-27 cells under NG and SMG are presented in Fig. 1. The value of the parameters $R^{2} Y$ and $Q^{2}$ are $>0.5$, which suggests that the model was good and that the prediction capability was strong. The greater the separation degree between the two groups, the more significant the classification effect. Compl refers to the first principal component interpretation degree and Comp2 refers to the second principal component interpretation degree. The metabolites of NG and SMG cells were grouped, indicating that there was a difference in metabolites between the two groups. A total of 67 differentially regulated metabolites were identified, including 36 upregulated and 31 downregulated metabolites (all $\mathrm{P}<0.05$, VIP $>1)$. Compared with the NG group, phosphatidyl ethanolamine (PE), phosphatidyl choline (PC), arachidonic acid and sphinganine were significantly upregulated in the SMG group, whereas sphingomyelin (SM), phosphatidyl serine (PS), phosphatidic acid (PA), L-Proline, creatine, pantothenic acid, oxidized glutathione (GSSG), adenosine diphosphate (ADP) and adenosine triphosphate (ATP) were significantly downregulated.

Lipids and lipid-like metabolite alterations of HGC-27 cells in $N G$ and SMG. The HMDB method in LC-MS was used to assess compound classification of HGC-27 cells. Compared with the NG groups, HMDB compound analysis confirmed that glyceropholipids (45.10\%) and fatty acids (13.73\%) were the most affected by SMG, followed by nucleotides (Fig. 2). Of the 67 metabolites, LC-MS/MS profiling of HGC-27 cells detected 50 lipid molecules, including 31 phospholipids and 7 sphingolipids, which were upregulated in SMG (Table I). These results suggest that these two types of lipids exhibited special biological behaviors in HGC-27 cells under SMG. 


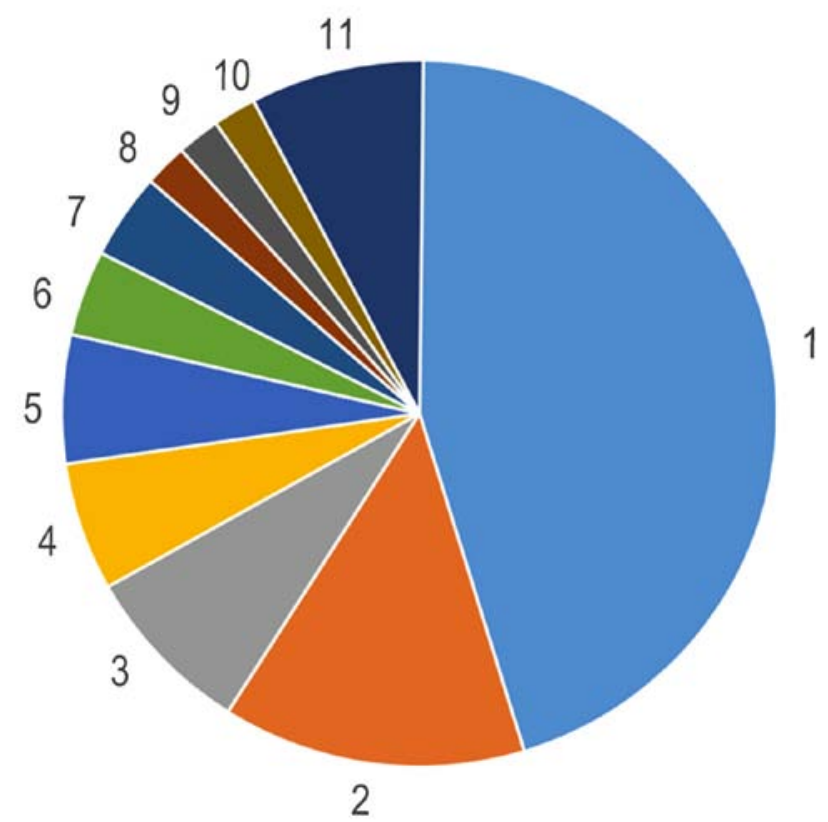

Figure 2. Human Metabolme Database compound classification analysis of the significantly altered metabolites indicating that lipids were the mo st influenced metabolite under simulated microgravity. 1, Glycerophospholipids (45.1\%); 2, Fatty Acids (13.73\%); 3, Carboxylic acids and derivatives (7.84\%); 4, Prenol lipids (5.88\%); 5, Sphingolipids (5.88\%); 6, Organonitrogen Compounds (3.92\%); 7, Organooxygen compounds (3.92\%); 8, Alcohols and polyols (1.96\%); 9, Carbonyl compounds (1.96\%); 10, Flavonoids (1.96\%) and 11 , Others $(7.85 \%)$

A total of 38 significantly affected lipids, particularly phospholipids and sphingolipids, were observed, which characterized the differences between NG and SMG ( VIP>1). Detailed information concerning these lipids is presented in Table II. Of these 38 lipids, 25 were upregulated and 13 were downregulated. The two predominant downregulated lipid classes detected in SMG were SM and PS. It was showed that PS [DiMe (11,3)/MonoMe (11,5)] , PS [18:3 (9Z,12Z,15Z)/22:1(13Z)], PS [14:1 (9Z)/24:0)], PA[16:0/18:1(11Z)], SM (d18:0/16:1(9Z) and SM (d18: +B5:G321/14:0) levels significantly decreased, whereas Sphinganine, lactosylceramide (d18:1/12:0) and dihydroceramide levels increased under SMG.

Among the 13 downregulated lipids one class of PS [14:1(9Z)/24:0] (consisting of one chain of myristoleic acid at the $\mathrm{C}-1$ position and one chain of lignoceric acid at the C-2 position; http://www.hmdb.ca/metabolites/HMDB0112319), one class of $\mathrm{SM}(\mathrm{d} 18: 1 / 14: 0)$, three classes of $\mathrm{PE}$, [15:0/18:2(9Z,12Z), 15:0/20:2(11Z,14Z), 16:1(5Z)/16:1(5Z) and PE-NMe2 14:1(9Z)/16:1(9Z)] were downregulated after 1 and 3 days of SMG compared with the NG group, $(\mathrm{P}<0.05$; Fig. 3). Glucosylceramide (d18:1/18:0) was downregulated after 1 and 3 days of SMG compared with the NG group, however there was no statistical significance $(\mathrm{P}>0.05 ;$ Fig. 3$)$. Regarding lactosylceramide (d18:1/12:0), there was a significant increase after 3 days of SMG exposure compared with 1 day of SMG (Fig. 3).

The influence of fatty acid $\beta$-oxidation under SMG. Carnitines, including 3-hydroxyhexadecanoyl carnitine, 2-methylbutyroylcarnitine, isobutyryl carnitine and
Table I. Quantitated lipid classes and numbers in HGC-27 cells under normal gravity and simulated microgravity.

\begin{tabular}{|c|c|c|}
\hline Lipid category & Lipid class & $\begin{array}{l}\text { Number of } \\
\text { lipid species }\end{array}$ \\
\hline \multirow[t]{6}{*}{ Phospholipid } & Phosphatidylcholine & 13 \\
\hline & Lysophospholipid & 1 \\
\hline & Glycerophosphocholine & 1 \\
\hline & Phosphatidylethanolamine & 12 \\
\hline & Phosphatidylserine & 3 \\
\hline & Phosphatidic acid & 1 \\
\hline \multirow[t]{6}{*}{ Sphingolipid } & Sphingomyelin & 2 \\
\hline & Sphinganine & 1 \\
\hline & Oleamide & 1 \\
\hline & Linoleamide & 1 \\
\hline & Dihydroceramide & 1 \\
\hline & Lactosylceramide & 1 \\
\hline Glycerolipide & Glycinoprenol 9 & 1 \\
\hline \multirow[t]{11}{*}{ Other lipids } & Umbelliprenin & 1 \\
\hline & Sorbitan stearate & 1 \\
\hline & Pantothenic Acid & 1 \\
\hline & Oleoylcarnitine & 1 \\
\hline & Isobutyryl carnitine & 1 \\
\hline & Glycocholic acid & 1 \\
\hline & Camelliagenin B & 1 \\
\hline & Arachidonic acid & 1 \\
\hline & 8-Hydroxyguanosine & 1 \\
\hline & $\begin{array}{l}\text { 3-Hydroxyhexadecanoyl } \\
\text { carnitine }\end{array}$ & 1 \\
\hline & 2-Methylbutyroylcarnitine & 1 \\
\hline Total lipids & & 50 \\
\hline
\end{tabular}

oleoylcarnitine, serve a role in the oxidation of fatty acids to ATP (29). 3-hydroxyhexadecanoyl carnitine and isobutyryl carnitine were downregulated after 1 and 3 days of SMG compared with the NG group. However, 2-methylbutyroylcarnitine and oleoylcarnitine were only downregulated after 1 day of SMG. Furthermore, ATP and ADP were downregulated after 1 and 3 days of SMG compared with the NG group (Fig. 4).

KEGG pathway enrichment analysis. Fig. 5 shows the KEGG enrichment pathways under SMG. These pathways could be grouped into six categories: Cellular processes; environmental information processing; genetic information processing; human diseases; metabolism; and organismal systems. The results show that SMG significantly affected multiple pathways and KEGG pathway enrichment analysis showed that the differentially expressed metabolites were primarily associated with: Regulation of the lysosome; 'FoxO signaling pathway'; 'leishmaniasis'; 'GnRH signaling pathway'; 'platelet activation'; 'sphingolipid signaling pathway'; 'Fc $\gamma$ R-mediated phagocytosis'; 'long-term depression'; 'sphingolipid metabolism'; and 'arginine and proline metabolism'. 
Table II. Identification of the significantly altered metabolites in HGC-27 cells.

\begin{tabular}{|c|c|c|c|c|c|}
\hline Metabolite & Formula & $\mathrm{M} / \mathrm{Z}$ & P-value & Regulation & VIP \\
\hline SM (d18:+B5:G321/14:0) & $\mathrm{C}_{37} \mathrm{H}_{75} \mathrm{~N}_{2} \mathrm{O}_{6} \mathrm{P}$ & 719,5313 & $8.951 \times 10^{-6}$ & Downregulated & 1,5850 \\
\hline SM [d18:0/16:1(9Z)] & $\mathrm{C}_{39} \mathrm{H}_{79} \mathrm{~N}_{2} \mathrm{O}_{6} \mathrm{P}$ & 747,5634 & $2.004 \times 10^{-2}$ & Downregulated & 1,8047 \\
\hline PS [DiMe(11,3)/MonoMe $(11,5)]$ & $\mathrm{C}_{47} \mathrm{H}_{80} \mathrm{NO}_{12} \mathrm{P}$ & 918,4877 & $1.500 \times 10^{-8}$ & Downregulated & 1,1943 \\
\hline PS [18:3(9Z,12Z,15Z)/22:1(13Z)] & $\mathrm{C}_{46} \mathrm{H}_{82} \mathrm{NO}_{10} \mathrm{P}$ & 822,5620 & $9.948 \times 10^{-3}$ & Downregulated & 1,2988 \\
\hline PS [14:1(9Z)/24:0] & $\mathrm{C}_{44} \mathrm{H}_{84} \mathrm{NO}_{10} \mathrm{P}$ & 800,5760 & $1.440 \times 10^{-7}$ & Downregulated & 3,0884 \\
\hline PE-NMe2 [14:1(9Z)/16:1(9Z)] & $\mathrm{C}_{37} \mathrm{H}_{70} \mathrm{NO}_{8} \mathrm{P}$ & 732,4793 & $2.400 \times 10^{-8}$ & Downregulated & 3,9878 \\
\hline PE-NMe [14:1(9Z)/16:1(9Z)] & $\mathrm{C}_{36} \mathrm{H}_{68} \mathrm{NO}_{8} \mathrm{P}$ & 718,4649 & $4.190 \times 10^{-6}$ & Downregulated & 1,0028 \\
\hline PE (15:0/P-16:0) & $\mathrm{C}_{36} \mathrm{H}_{72} \mathrm{NO}_{7} \mathrm{P}$ & 706,4990 & $1.223 \times 10^{-6}$ & Upregulated & 1,8137 \\
\hline PE [15:0/24:1(15Z)] & $\mathrm{C}_{44} \mathrm{H}_{86} \mathrm{NO}_{8} \mathrm{P}$ & 832,6037 & $4.555 \times 10^{-3}$ & Upregulated & 1,3361 \\
\hline PE [15:0/22:5(4Z,7Z,10Z,13Z,16Z)] & $\mathrm{C}_{42} \mathrm{H}_{74} \mathrm{NO}_{8} \mathrm{P}$ & 796,5100 & $7.155 \times 10^{-4}$ & Upregulated & 1,4220 \\
\hline PE [15:0/22:4(7Z,10Z,13Z,16Z)] & $\mathrm{C}_{42} \mathrm{H}_{76} \mathrm{NO}_{8} \mathrm{P}$ & 798,5255 & $2.232 \times 10^{-2}$ & Upregulated & 1,3835 \\
\hline PE [15:0/22:2(13Z,16Z)] & $\mathrm{C}_{42} \mathrm{H}_{80} \mathrm{NO}_{8} \mathrm{P}$ & 802,5564 & $1.816 \times 10^{-2}$ & Downregulated & 2,8050 \\
\hline PE [15:0/22:1(13Z)] & $\mathrm{C}_{42} \mathrm{H}_{82} \mathrm{NO}_{8} \mathrm{P}$ & 804,5728 & $7.846 \times 10^{-5}$ & Upregulated & 4,1810 \\
\hline PE [15:0/20:2(11Z,14Z)] & $\mathrm{C}_{40} \mathrm{H}_{76} \mathrm{NO}_{8} \mathrm{P}$ & 774,5259 & $9.433 \times 10^{-6}$ & Downregulated & 8,3376 \\
\hline PE [15:0/18:2(9Z,12Z)] & $\mathrm{C}_{38} \mathrm{H}_{72} \mathrm{NO}_{8} \mathrm{P}$ & 746,4948 & $1.153 \times 10^{-6}$ & Downregulated & 4,9712 \\
\hline PE [14:0/24:1(15Z)] & $\mathrm{C}_{43} \mathrm{H}_{84} \mathrm{NO}_{8} \mathrm{P}$ & 818,5870 & $9.771 \times 10^{-6}$ & Upregulated & 1,1963 \\
\hline PE [14:0/20:2(11Z,14Z)] & $\mathrm{C}_{39} \mathrm{H}_{74} \mathrm{NO}_{8} \mathrm{P}$ & 757,5542 & $4.356 \times 10^{-3}$ & Downregulated & 2,1212 \\
\hline PC [o-16:0/20:4(8Z,11Z,14Z,17Z)] & $\mathrm{C}_{44} \mathrm{H}_{82} \mathrm{NO}_{7} \mathrm{P}$ & 812,5771 & $1.832 \times 10^{-2}$ & Upregulated & 1,2528 \\
\hline PC [22:5(4Z,7Z,10Z,13Z,16Z)/16:0] & $\mathrm{C}_{46} \mathrm{H}_{82} \mathrm{NO}_{8} \mathrm{P}$ & 852,5716 & $4.918 \times 10^{-2}$ & Upregulated & 2,0817 \\
\hline PC [22:4(7Z,10Z,13Z,16Z)/14:0] & $\mathrm{C}_{44} \mathrm{H}_{80} \mathrm{NO}_{8} \mathrm{P}$ & 826,5566 & $7.767 \times 10^{-6}$ & Upregulated & 3,9909 \\
\hline PC [18:4(6Z,9Z,12Z,15Z)/P-18:0] & $\mathrm{C}_{44} \mathrm{H}_{80} \mathrm{NO}_{7} \mathrm{P}$ & 810,5616 & $3.320 \times 10^{-7}$ & Upregulated & 2,0711 \\
\hline PC [18:4(6Z,9Z,12Z,15Z)/P-16:0] & $\mathrm{C}_{42} \mathrm{H}_{76} \mathrm{NO}_{7} \mathrm{P}$ & 782,5270 & $1.608 \times 10^{-5}$ & Upregulated & 1,0437 \\
\hline PC [18:1(11Z)/22:6(4Z,7Z,10Z,13Z,16Z,19Z)] & $\mathrm{C}_{48} \mathrm{H}_{82} \mathrm{NO}_{8} \mathrm{P}$ & 876,5722 & $2.134 \times 10^{-4}$ & Upregulated & 1,7139 \\
\hline PC [18:0/20:4(5Z,8Z,11Z,14Z)] & $\mathrm{C}_{46} \mathrm{H}_{84} \mathrm{NO}_{8} \mathrm{P}$ & 854,5879 & $9.655 \times 10^{-6}$ & Upregulated & 1,5839 \\
\hline PC [18:0/18:2(9Z,12Z)] & $\mathrm{C}_{44} \mathrm{H}_{84} \mathrm{NO}_{8} \mathrm{P}$ & 830,5881 & $6.867 \times 10^{-4}$ & Upregulated & 2,3650 \\
\hline PC [16:1(9Z)/20:3(5Z,8Z,11Z)] & $\mathrm{C}_{44} \mathrm{H}_{80} \mathrm{NO}_{8} \mathrm{P}$ & 826,5554 & $1.198 \times 10^{-4}$ & Upregulated & 1,5843 \\
\hline PC [16:1(9Z)/16:1(9Z)] & $\mathrm{C}_{40} \mathrm{H}_{76} \mathrm{NO}_{8} \mathrm{P}$ & 752,5196 & $2.971 \times 10^{-2}$ & Downregulated & 4,8632 \\
\hline PC [16:0/20:5(5Z,8Z,11Z,14Z,17Z)] & $\mathrm{C}_{44} \mathrm{H}_{78} \mathrm{NO}_{8} \mathrm{P}$ & 824,5400 & $9.291 \times 10^{-3}$ & Upregulated & 3,4401 \\
\hline PC [16:0/20:3(5Z,8Z,11Z)] & $\mathrm{C}_{44} \mathrm{H}_{82} \mathrm{NO}_{8} \mathrm{P}$ & 826,5554 & $6.358 \times 10^{-3}$ & Upregulated & 1,4770 \\
\hline PC (16:0/18:3(6Z,9Z,12Z)] & $\mathrm{C}_{42} \mathrm{H}_{78} \mathrm{NO}_{8} \mathrm{P}$ & 800,5412 & $9.244 \times 10^{-4}$ & Upregulated & 2,2188 \\
\hline PA (16:0/18:1(11Z)] & $\mathrm{C}_{37} \mathrm{H}_{71} \mathrm{O}_{8} \mathrm{P}$ & 719,4839 & $4.759 \times 10^{-6}$ & Downregulated & 1,2779 \\
\hline LysoPC [20:4(8Z,11Z,14Z,17Z)] & $\mathrm{C}_{28} \mathrm{H}_{50} \mathrm{NO}_{7} \mathrm{P}$ & 588,3274 & $5.778 \times 10^{-5}$ & Upregulated & 1,7989 \\
\hline Sphinganine & $\mathrm{C}_{18} \mathrm{H}_{39} \mathrm{NO}_{2}$ & 302,3052 & $6.998 \times 10^{-3}$ & Upregulated & 2,7342 \\
\hline Oleamide & $\mathrm{C}_{18} \mathrm{H}_{35} \mathrm{NO}$ & 563,5495 & $7.274 \times 10^{-4}$ & Upregulated & 31,6443 \\
\hline Linoleamide & $\mathrm{C}_{18} \mathrm{H}_{33} \mathrm{NO}$ & 280,2632 & $1.702 \times 10^{-2}$ & Upregulated & 10,9674 \\
\hline Lactosylceramide (d18:1/12:0) & $\mathrm{C}_{42} \mathrm{H}_{79} \mathrm{NO}_{13}$ & 850,5563 & $5.000 \times 10^{-9}$ & Upregulated & 3,5254 \\
\hline Glycerophosphocholine & $\mathrm{C}_{8} \mathrm{H}_{20} \mathrm{NO}_{6} \mathrm{P}$ & 258,1098 & $1.328 \times 10^{-2}$ & Upregulated & 1,5225 \\
\hline Dihydroceramide & $\mathrm{C}_{19} \mathrm{H}_{39} \mathrm{NO}_{3}$ & 362,3264 & $2.622 \times 10^{-2}$ & Upregulated & 1,9767 \\
\hline
\end{tabular}

VIP, variable importance; M/Z, mass-to-charge ratio; SM, sphingomyelin; PS, phosphatidylserine; PE, phosphatidylethanolamine; PC, phosphatidylcholine; PA, phosphatidic acid; LysoPC, lysophosphatidylcholine.

\section{Discussion}

Several studies have explored the effects of different durations of NG and SMG on various types of cells, ranging from a few seconds to dozens of days, reporting notable effects on different types of cells, including thyroid, colorectal and breast cancer cells (30-33). In these studies cellular morphology was significantly altered (3D spheroid structure formation and the alteration of the cytoskeleton), the extracellular matrix (ECM) was increased, the cell cycle was modified after 10 and 12 days of SMG (the number of cells in the $\mathrm{G}_{1}$ phase increased, whilst the number of cells in the $S$ and $G_{2} / M$ phases decreased), proliferation capacity was decreased and apoptosis was increased $(30,31)$. The clear alteration of physiological functions of different human cancer cells were observed in our previous study (34). Chen et al (26) reported that different types of tumor can reprogram their metabolic processes to fulfill particular demands after 5 days of SMG, including processes involved 
A
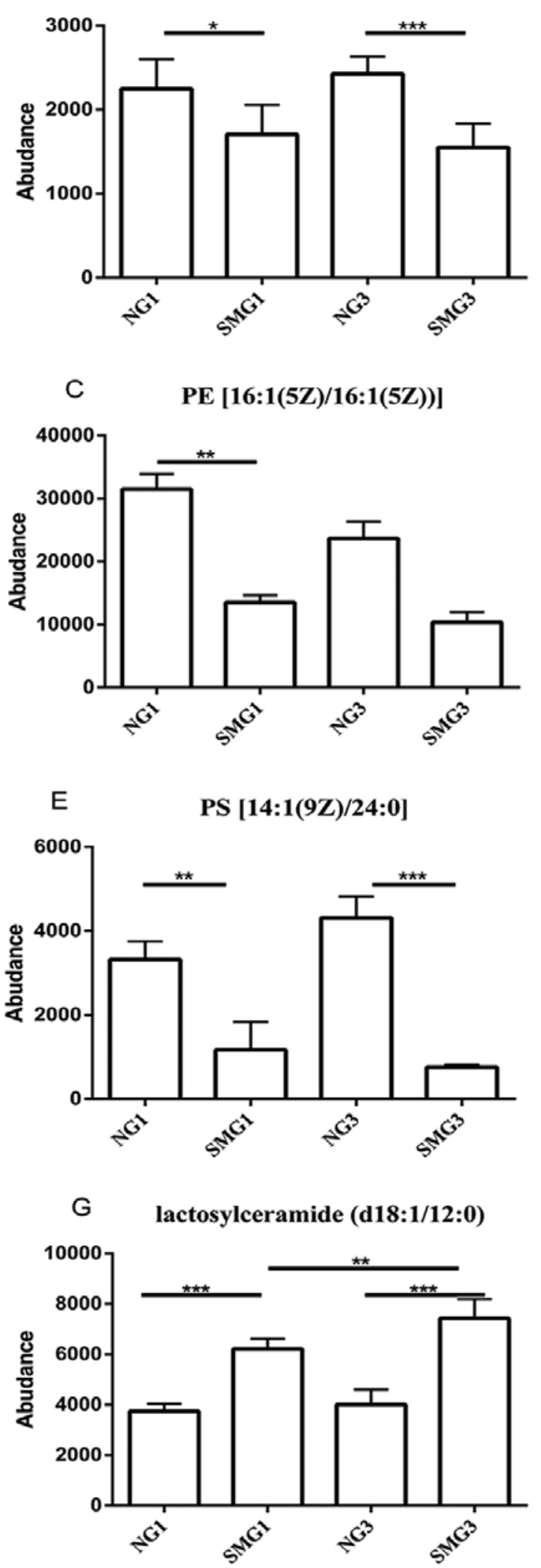

B PE [15:0/20:2(11Z,14Z)]

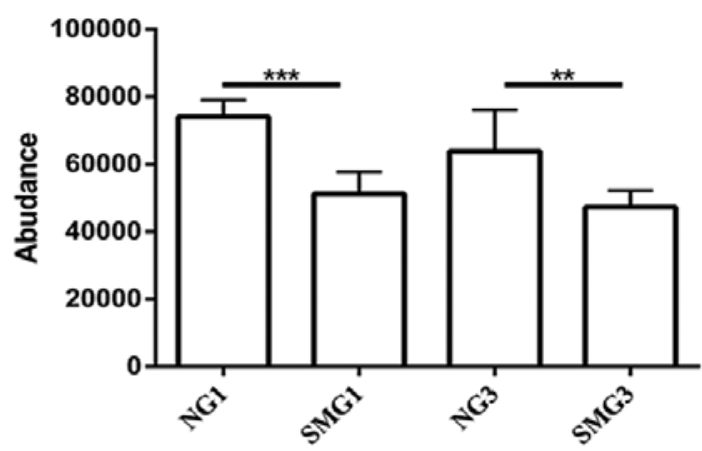

D PE-NMe2 [14:1(9Z)/16:1(9Z]

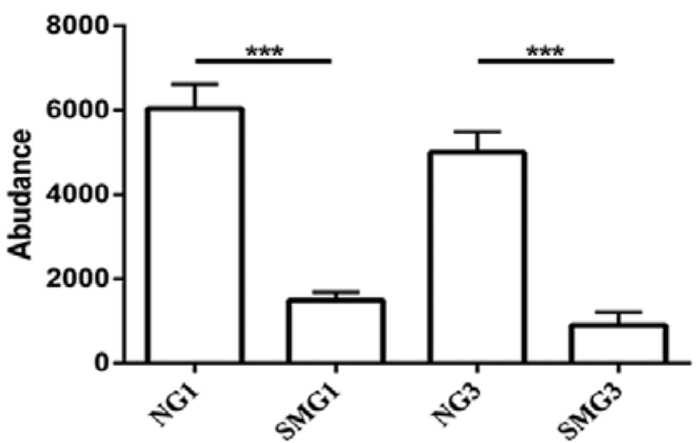

F Glucosylceramide (d18:1/18:0)

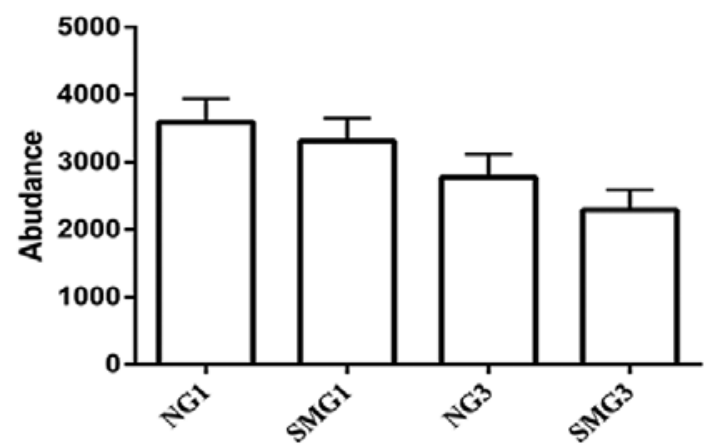

H PE [15:0/18:2(9Z,12Z)]

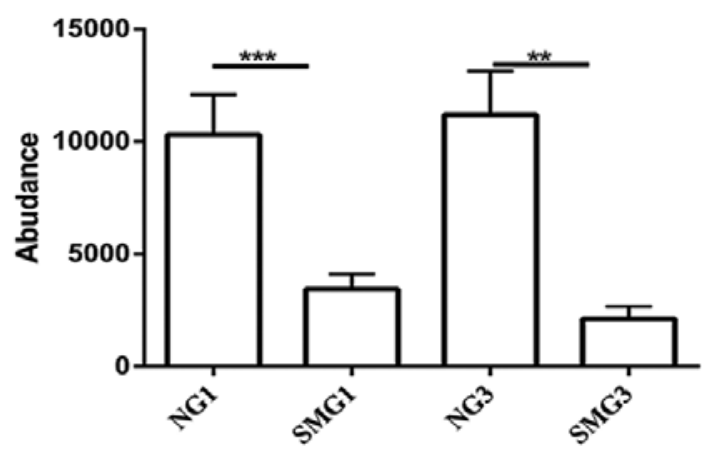

Figure 3. Effects of SMG on the expression of (A) SM (d18:1/14:0), (B) PE [15:0/20:2(11Z,14Z)], (C) PE [16:1(5Z)/16:1(5Z)], (D) PE-NMe2 [14:1(9Z)/16:1(9Z)], (E) PS [14:1(9Z)/24:0], (F) Glucosylceramide (d18:1/18:0), (G) Lactosylceramide (d18:1/12:0) and (H) PE [15:0/18:2(9Z,12Z)]. ${ }^{*} \mathrm{P}<0.05$, ${ }^{* *} \mathrm{P}<0.01$ and ${ }^{* * * *} \mathrm{P}<0.001$. NG, normal gravity; SMG, simulated microgravity; D1, 1 day duration; D3, 3 day duration; PE, phosphatidyl ethanolamine; SM, sphingomyelin.

in cancer cell proliferation, metastasis, immunological escape and survival, and shifting the aggressive phenotype of cancer cells. This metabolic reprogramming is regarded as a novel characteristic of tumors (35). Chen et al (26) also proposed a novel point to understand the Warburg effect in MDA-MB-231 and MCF-7 breast cancer cells. Glycolysis is often induced 

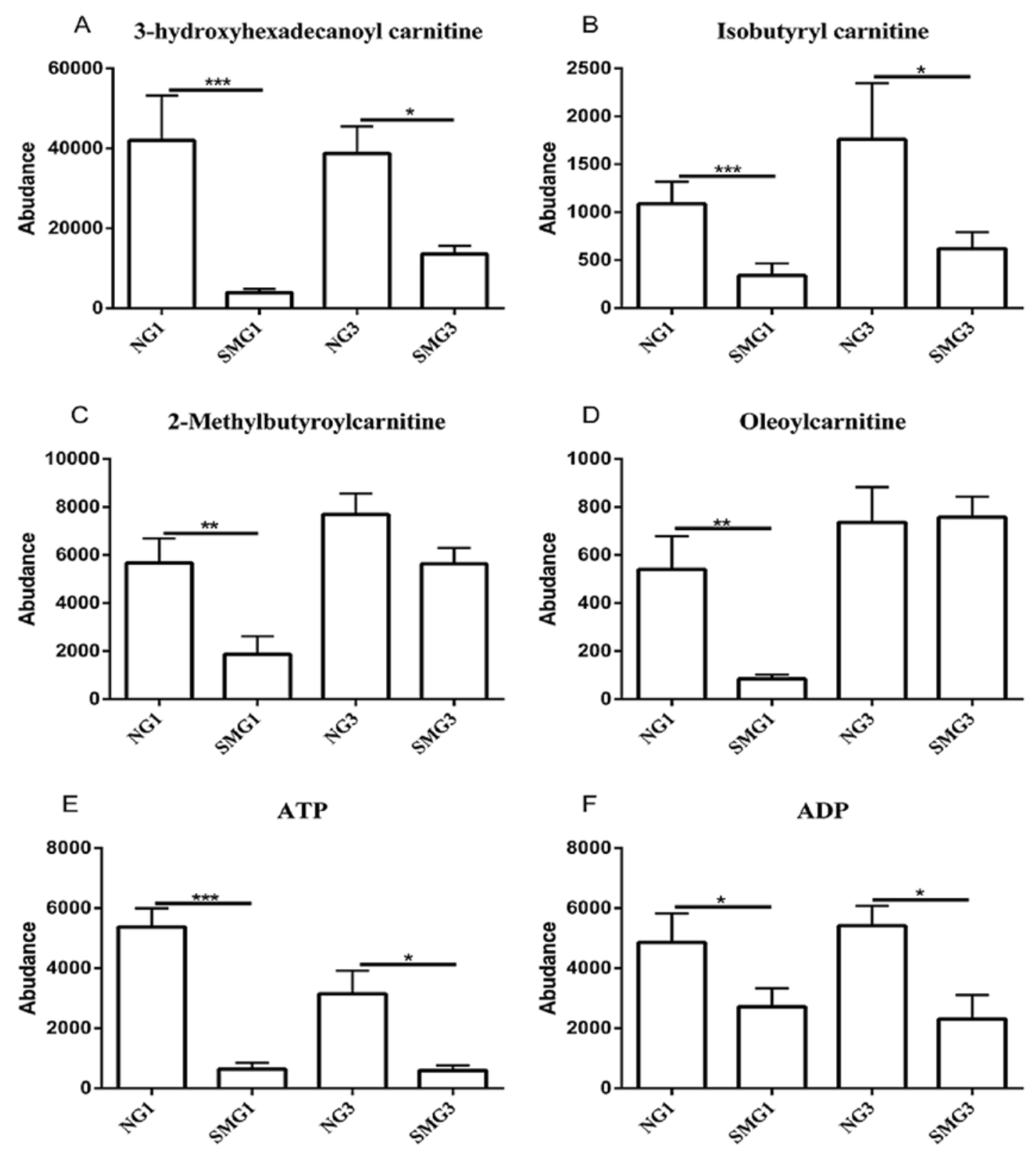

Figure 4.Effects of SMG on the expression of (A) 3-hydroxyhexadecanoyl carnitine, (B) Isobutyayl carnitine, (C) 2-Methylbutyroylcarnitine, (D) Oleoylcarbitine, (E) ATP and (F) ADP. ${ }^{*} \mathrm{P}<0.05,{ }^{* * *} \mathrm{P}<0.01$ and ${ }^{* * *} \mathrm{P}<0.001$. NG, normal gravity; SMG, simulated microgravity; D1, 1 day duration; D3, 3 day duration; ATP, adenosine triphosphate; ADP, adenosine diphosphate.

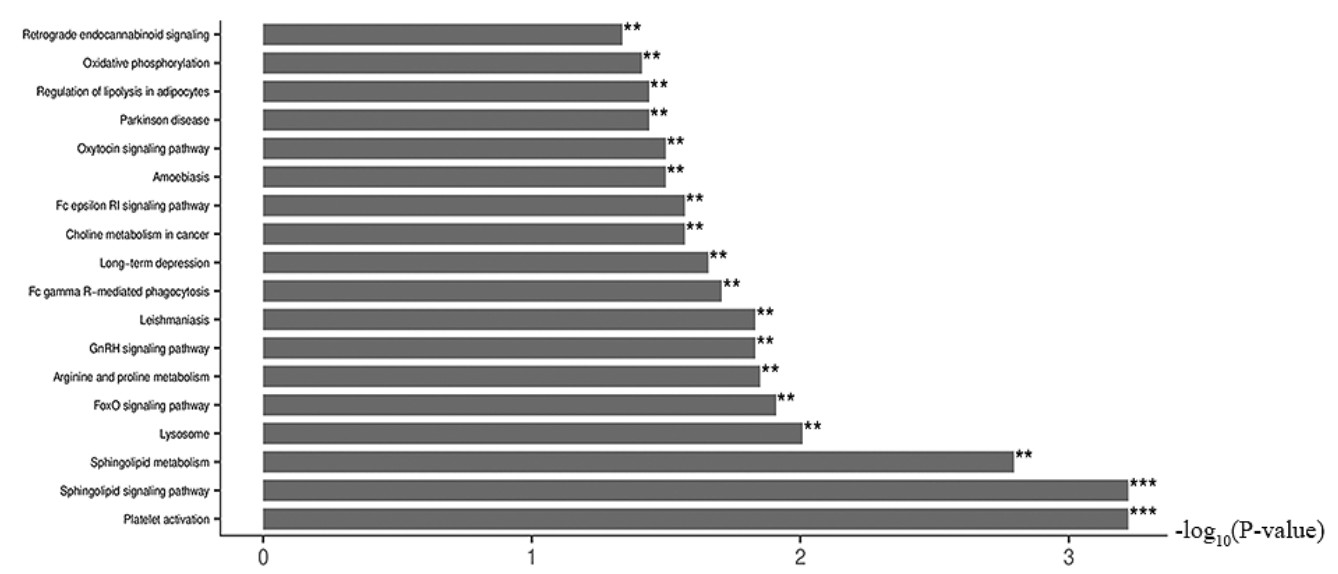

Figure 5. Kyoto Encyclopedia of Genes and Genomes pathway enrichment analysis of the significantly dysregulated metabolites with SMG. $\mathrm{x}$-axis is the $-\log _{10}\left(\mathrm{P}\right.$-value). ${ }^{* *} \mathrm{P}<0.01$ and ${ }^{* * *} \mathrm{P}<0.001$. Fox $\mathrm{O}$, forkhead box $\mathrm{O}$. 
by hypoxia; however, glycolysis can also be induced by high levels of adrenomedullin under SMG, which may be a novel mechanism inducing glycolysis. However, to the best of our knowledge, the exact molecular mechanism of this reprogramming in tumor cells remains unknown under SMG.

A previous study reported that $72 \mathrm{~h}$ exposure to SMG induces changes in morphology, proliferation, cell cycle distribution and apoptosis in human SGC-7901 gastric cancer cells (36). Thus, the present study investigated whether 1 and 3 days exposure to SMG could influence the metabolites of human HGC-27 gastric cancer cells. Previous studies have demonstrated that SMG influences several metabolic pathways, stimulates lipid metabolism and interrupting the Krebs cycle in human breast cancer cells, osteoblast and oligodendrocyte after $5 \mathrm{~d}, 110 \mathrm{~h}$ and $3 \mathrm{~d}$ of SMG, respectively $(26,27,37)$.

The present study demonstrated that SMG significantly affected HGC-27 human gastric cancer cells in a number of processes, in particular lipid metabolism. HGC-27 cells are highly malignant tumor cells (38). Reprograming lipid metabolism is associated with cancer invasion and metastasis (39); however, the influences of lipid metabolism on HGC-27 cells remains unclear. In the present study, HGC-27 lipid metabolites were measured using LC-MS and, to the best of our knowledge, this is the first study to analyze the alteration of lipid metabolic profiles of gastric cancer cells under SMG. As evidenced by LC-MS metabolome analysis, it was revealed the differential expression of 67 metabolites were altered during 1 and 3 days exposure to SMG compared with NG, according to the criteria of a VIP $>1$ and $\mathrm{P}<0.05$, suggesting several different categories of membrane lipid components were affected by SMG. A total of 50 significantly different lipid metabolites were identified and 1 and 3 days exposure to SMG significantly increased the levels of PE, PC, arachidonic acid and sphinganine, but significantly decreased the levels of SM, PS, PA, pantothenic acid, ADP and ATP (Table I, Fig. 4). These upregulated and downregulated metabolites are associated with cellular processes, biological regulation and metabolic processes. These metabolites, altered in SMG, may have value as markers for the early diagnosis of gastric cancer.

PC, PE, PS, SM and PA are the primary components of membrane phospholipids, which play a significant role in cell membranes (40). A previous study showed that these phospholipids were upregulated in breast cancer tissues (41). The high levels of PE may serve as a biomarker of apoptosis in cancer (42) and PC has been considered as a biomarker of membrane proliferation in ovarian cancer (43). The present study demonstrated that PE and PC levels increased under SMG. Previous studies have indicated that several cancer cell lines, including ML-1 and ONCO-DG1 thyroid carcinoma cells, SGC-7901 gastric carcinoma cells, U251 glioma cells and MDA-MB-231 breast cancer cells, exhibit high levels of apoptosis under SMG after 48, 24, 36, 8 and $72 \mathrm{~h}$ of SMG (36,44-47). These high levels of apoptosis may be due to elevated PC levels, which indicates high membrane proliferation. These results are consistent with previous findings that apoptosis in human SGC-7901 gastric cancer cells increase following treatment with SMG after $48 \mathrm{~h}$ (36). However, other PEs, such as PE [15:0/18:2(9Z,12Z)], PE [15:0/20:2(11Z,14Z)], PE [16:1(5Z)/16:1(5Z)] and PE-NMe2 [14:1(9Z)/16:1(9Z)] were downegulated after 1 and 3 days of SMG compared with the NG group. It is hypothesized that PE is an key molecule for the synthesis of glycosylphosphatidylinositol anchors, which are glycolipids identified in yeast, protozoa, plants and humans, enabling modified proteins to be tethered to the outer leaflet of the plasma membrane necessary for the immune response, cell-cell communication and embryogenesis (48-51). Failure to attach can lead to dysfunction in the immune response, cell-cell communication and embryogenesis. As levels of PE were decreased in HGC-27 cells in the present study after 1 and 3 days of SMG, an adverse effect, such as gene mutations associated with cell cycle and apoptosis, may occur.

Chang et al (52) and Qian et al (53) observed that the invasive ability of A549 human lung adenocarcinoma and MCF-7 breast cells decreases following treatment with SMG after $72 \mathrm{~h}$. A previous study reported that PS is associated with invasion of colorectal cancer cells (54). In the present study, it was demonstrated that PS [DiMe $(11,3) /$ MonoMe $(11,5)]$, PS [18:3 (9Z,12Z,15Z)/22:1(13Z)] and PS [14:1 (9Z)/24:0)] significantly decreased, suggesting that the the invasive ability of HGC-27 cells was weakened under SMG. This indicates that these phospholipids may have value as biomarkers for metastasis.

$\mathrm{SM}$ is located in the plasma membrane of most mammalian cells, which is the primary component of the pulp. The metabolic products of SM, including Cer and sphingosine (Sph), are signalling molecules with biological activity and act as first and/or second messengers controlling the vital activity of cells, such as cell growth, differentiation, aging, and apoptosis (55-57). The present study observed that SM (d18:0/16:1(9Z) and SM (d18: +B5:G321/14:0) levels were decreased, whereas Sphinganine, lactosylceramide (d18:1/12:0) and dihydroceramide levels increased under SMG (Table II). These results suggest that SMG may decrease the formation of sphingomyelin and increase its metabolism. Cer and Sph metabolic products function in the regulation of tumor proliferation and apoptosis, and are negative regulators of proliferation, which can inhibit cell growth and promote apoptosis (58). PE and the metabolic products of SM (Cer and $\mathrm{Sph}$ ) can contribute to the increase in apoptosis under SMG $(59,60)$. Previous studies have demonstrated a decrease in the proliferation capacity in SGC-7901 gastric cancer cells, U251 glioma cells and A549 lung adenocarcinoma cells, and increased apoptosis after 12, 48 and $72 \mathrm{~h}$ of SMG, respectively $(36,47,53)$.

SM metabolism can regulate the function of K-Ras, which was the first human oncogene identified in human cancer and is a member of the Ras superfamily (61). Considering cellular signalling networks in the Ras-Raf-mitogen-activated protein kinase (MAPK) pathways, the role of K-Ras is associated with cell physiological functions, such as proliferation, apoptosis and survival (62). Relevant mutations in pathway components, such as serine/threonine-protein kinase B-raf, epidermal growth factor receptor and neurofibromin, are associated with progression in colon cancer and melanomas (63-65). The present study demonstrated that PA[16:0/18:1(11Z)] levels were decreased after SMG compared with the NG group (Table II). This may be associated with the high levels of phospholipase D2 (PLD2) after 3 days of SMG (66). PLD2 is an enzyme which hydrolyzes $\mathrm{PA}$, promoting local invasion by regulating MT1-matrix metalloproteinase (MMP) (66). Based on the 
role of PLD2-generated PA in breast cancer metastasis, PLD2 may be regarded as a potential therapeutic target for metastatic breast cancer, and as a plasma membrane target (67). MT1-MMP, tethered to the plasma membrane, is a key protein associated with the migration of cancer cells (67). PLD2 generates small lipid molecules, such as phosphatidic acid, which can regulate the movement of the cytoskeleton, proliferation and migration (68-70). Therefore, it has been suggested that PLD2 and its small lipid molecules can regulate MT1-MMP for invasion and metastasis. However, this result contradicts the data of the present study, which demonstrates that some lipid levels, including PS [DiMe(11,3)/MonoMe(11,5)], PS [18:3(9Z,12Z,15Z)/22:1(13Z)] and PS [14:1(9Z)/24:0], were significantly decreased under SMG, suggesting that the invasive abilities of HGC-27 cells are weakened under SMG. It was hypothesized that the environment of cell proliferation may account for these contradicting results. Furthermore, the different devices used to simulate microgravity, such as random positioning machine and RCCS are speculated to account for the alteration in cell migration; however, further studies are required.

L-Proline, creatine, ADP and ATP levels were decreased after 1 and 3 days of SMG compared with the NG group in the present study. The downregulation of L-Proline in HGC-27 cells under SMG may be due to decreased activation of MMPs and degradation of the microenvironment for the ECM (71), rather than the degradation of collagen, which is regulated under conditions of nutrient stress assoicated with the mTOR signaling pathway, is blocked (72). However, the mTOR pathway participates in the process of apoptosis and autophagy (73).

The present study demonstrated that 3-hydroxyhexadecanoyl carnitine, 2-methylbutyroylcarnitine, isobutyryl carnitine and oleoylcarnitine, associated with $\beta$-oxidation, were significantly downregulated under SMG. Creatine is a key component in muscle contraction and can be transported between the mitochondria and cellular ATP utilization sites, acting as a spatial energy buffer (74). The function of creatine in cancer has been studied, reporting that some physiological functions of cancer, such as metabolism, are associated with the creatine kinase system, by regulating ATP provisions (75). The anticancer role of creatine has been demonstrated in vitro and in vivo experimental models $(76,77)$. The downregulation of creatine, ADP and ATP in present study indicates that SMG may influence energy metabolism, an important process in physiological functions, including proliferation, cell cycle, migration and apoptosis after $5 \mathrm{~d}$ of expose (26). ATP is produced primarily in the mitochondria. SMG may have interferred with the normal mitochondrial function of HGC-27 gastric cancer cells, which has been illustrated in skeletal muscle tissue and cardiomyocytes $(78,79)$. Mitochondrial function alteration might be an adaptive response for HGC-27 cells to reprogram their metabolism for particular requirements under SMG (80). A previous study reported that glycolysis and the pentose phosphate pathways were dominant, whereas the Krebs cycle was interrupted, which resulted in the downregulation of ATP, after $110 \mathrm{~h}$ of SMG (27). Similarly, complex II, a primary protein of the mitochondrial respiratory chain, was decreased and ATP was influenced by a reduction in proton transport when measured by proteomics (27).
Pantothenic acid is associated with cell migration (81). The downregulation of pantothenic acid in the present study may be due to the decreased migration ability, which was consistent with our previous discussion that the invasive ability decreased from downregulating PS [DiMe(11,3)/MonoMe(11,5)], PS [18:3(9Z,12Z,15Z)/22:1(13Z)] and PS [14:1(9Z)/24:0]. Furthermore, the downregulation of pantothenic acid, the key precursor for the biosynthesis of coenzyme A (CoA), can inhibit the synthesis of CoA and, in the Krebs cycle, CoA is a key enzyme for the transformation of $\alpha$-ketoglutarate to succinyl-CoA (82).

Meanwhile, the KEGG pathway enrichment analysis of the present study revealed that the metabolites associated with the regulation of physiological functions were differentially expressed in SMG compared with NG. When the sphingolipid signaling pathway, sphingolipid metabolism, and arginine and proline metabolism were altered under SMG, their associated physiological functions, such as proliferation, cell cycle, apoptosis and migration, may also have been affected. Therefore, the mechanism of the effect of SMG on these functions in human HGC-27 cells requires further investigation. In addition, KEGG pathway enrichment analysis indicated that the differentially expressed metabolites were primarily associated with the Forkhead box O (FOXO) signaling pathway. FOXO is an important transcription factor that determines cell fate and is associated with a broad range of cellular physiological functions, such as differentiation, apoptosis, cell proliferation, DNA damage and repair and mediating oxidative stress among a wide range of cancers $(83,84)$. The intracellularly initiation pathway of apoptosis induced by the FOXO protein is associated with oxidative stress, which occurs when ROS is released into the cytoplasm (85). The FOXO1 and FOXO3a transcription factors typically actived during oxidative stress causing apoptotic cell injury $(86,87)$. Under other oxidative stresses, FOXO3a translocates from the cytoplasm to the nucleus where it triggers cell death, thus activating the cell apoptosis pathway mediated by the Fas protein (88). In addition, FOXO4 and FOXO3a can mediate cell cycle arrest in mice and cyclin-dependent kinases (CDK) expression through DNA damage (89). The transcription factor, E2F1 forms a complex with FOXO1 and FOXO3a, promoting the transition from $\mathrm{G}_{1}$ to $\mathrm{S}$ phase, eventually resulting in cell cycle arrest (90). Notably, knockdown of FOXO3a, in combination with the oncogene c-myc, nuclear factor and p27, results in the initiation of the cell cycle, alteration of malignant mouse cells and activation of carcinogenesis (91).

In summary, the investigation of cancer cells under SMG may provide novel insight into the development of cancer and subsequent changes in physiological function. The present study revealed that human HGC-27 gastric cancer cells have a major effect on lipid metabolism and that SMG may be valuble for cell and cancer research. Ground-based weightlessness simulators like the RCCS, used in the present study, have improved the understanding of how SMG may affect humans. Although the present study is the first to show the changes in metabolic expression of human HGC-27 gastric cancer cells induced by SMG, to the best of our knowledge, the understanding is far from complete. However, the results of the present study may inform future development of novel targets for gastric cancer therapy. 


\section{Acknowledgements}

Not applicable.

\section{Funding}

The present study was funded by The Key Program Grants of PLA Planning Technology Research (grant no. SYFD1500128).

\section{Availability of data and materials}

The datasets used and/or analyzed during the present study are available from the corresponding author upon reasonable request.

\section{Authors' contributions}

ZC performed the experiments and drafted the initial manuscript. HS, SG, JZ and BL performed the majority of the experiments and statistical analyses. JY, SC, HFY, PS and TZ performed certain experiments and collected the samples. NJ, SG, JZ and HMY interpreted the data. YC designed the study and revised the initial manuscript. All authors read and approved the final manuscript.

\section{Ethical approval and consent to participate}

Not applicable.

\section{Patient consent for publication}

Not applicable.

\section{Competing interests}

The authors declare that they have no competing interests.

\section{References}

1. Fedotov AA, Akulov SA and Akulova AS: Alterations in cardiovascular system under artificially simulated microgravity: Preliminary study. Conf Proc IEEE Eng Med Biol Soc 2016: 204-206, 2016.

2. Atomi Y: Gravitational Effects on human physiology. Subcell Biochem 72: 627-59, 2015.

3. Hughes-Fulford M: Changes in gene expression and signal transduction in microgravity. J Gravit Physiol 8: P1-4, 2001.

4. Ulbrich C, Wehland M, Pietsch J, Aleshcheva G, Wise P, van Loon J, Magnusson N, Infanger M, Grosse J, Eilles C, et al: The impact of simulated and real microgravity on bone cells and mesenchymal stem cells. Biomed Res Int 2014: 928507, 2014.

5. Riwaldt S, Bauer J, Wehland M, Slumstrup L, Kopp S, Warnke E, Dittrich A, Magnusson NE, Pietsch J, Corydon TJ, et al: Pathways regulating spheroid formation of human follicular thyroid cancer cells under simulated microgravity conditions: A genetic approach. Int J Mol Sci 17: 528, 2016.

6. Svejgaard B, Wehland M, Ma X, Kopp S, Sahana J, Warnke E, Aleshcheva G, Hemmersbach R, Hauslage J, Grosse J, et al: Common effects on cancer cells exerted by a randompositioning machine and a 2D clinostat. PLoS One 10: e0135157, 2015.

7. Sahana J, Nassef MZ, Wehland M, Kopp S, Krüger M, Corydon TJ, Infanger M, Bauer J and Grimm D: Decreased E-cadherin in MCF-7 human breast cancer cells forming multicellular spheroids exposed to simulated microgravity. Proteomics 18: e1800015, 2018.

8. Vidyasekar P, Shyamsunder P, Arun R, Santhakumar R, Kapadia NK, Kumar R and Verma RS: Genome wide expression profiling of cancer cell lines cultured in microgravity reveals significant dysregulation of cell cycle and MicroRNA gene networks. PLoS One 10: e0135958, 2015.
9. Dietz C, Infanger M, Romswinkel A, Strube F and Kraus A: Apoptosis induction and alteration of cell adherence in human lung cancer cells under simulated microgravity. Int J Mol Sci 20: pii: E3601, 2019.

10. Kim YJ, Jeong AJ, Kim M, Lee C, Ye SK and Kim S: Time-averaged simulated microgravity (taSMG) inhibits proliferation of lymphoma cells, L-540 and HDLM-2, using a 3D clinostat. Biomed Eng Online 16: 48, 2017.

11. Warburg O: On respiratory impairment in cancer cells. Science 124: 269-272, 1956.

12. Nath $\mathrm{S}$ and Villadsen J: Oxidative phosphorylation revisited. Biotechnol Bioeng 112: 429-437, 2015.

13. Hanahan D and Weinberg RA: Hallmarks of cancer: The next generation. Cell 144: 646-74, 2011.

14. Hu JD, Tang HQ, Zhang Q, Fan J, Hong J, Gu JZ and Chen JL: Prediction of gastric cancer metastasis through urinary metabolomics investigation using GC/MS. World J Gastroenterol 17: 727-734, 2011.

15. Chen JL, Tang HQ, Hu JD, Fan J, Hong J and Gu JZ: Metabolomics of gastric cancer metastasis detected by gas chromatography and mass spectrometry. World J Gastroenterol 16: 5874-5880, 2010.

16. Gatenby RA and Gillies RJ: Why do cancers have high aerobic glycolysis. Nat Rev Cancer 4: 891-899, 2004.

17. Koukourakis MI, Pitiakoudis M, Giatromanolaki A, Tsarouha A, Polychronidis A, Sivridis E and Simopoulos C: Oxygen and glucose consumption in gastrointestinal adenocarcinomas: Correlation with markers of hypoxia, acidity and anaerobic glycolysis. Cancer Sci 97: 1056-1060, 2006.

18. Pedersen PL, Mathupala S, Rempel A, Geschwind JF and Ko YH: A key player in the growth and survival of many cancers and an ideal prospect for therapeutic intervention. Biochim Biophys Acta 1555: 14-20, 2002.

19. Tech K, Tikunov AP, Faroog H, Morrissy AS, Meidinger J, Fish T, Green SC, Liu H, Li Y, Mungall AJ, et al: Pyruvate kinase inhibits proliferation during postnatal cerebellar neurogenesis and suppresses medulloblastoma formation. Cancer Res 77: 3217-3230, 2017.

20. An J, Zhang Y, He J, Zang Z, Zhou Z, Pei X, Zheng X, Zhang W, Yang $\mathrm{H}$ and $\mathrm{Li} \mathrm{S}$ : Lactate dehydrogenase A promotes the invasion and proliferation of pituitary adenoma. Sci Rep 7: 4734, 2017.

21. Israelsen WJ and Vander Heiden MG: Pyruvate kinase: Function, regulation and role in cancer. Semin Cell Dev Biol 43: 43-51, 2015.

22. Wu J, Hu L, Chen M, Cao W, Chen $\mathrm{H}$ and He T: Pyruvate kinase M2 overexpression and poor prognosis in solid tumors of digestive system: Evidence from 16 cohort studies. Onco Targets Ther 9: 4277-4288, 2016.

23. Jové M, Collado R, Quiles JL, Ramírez-Tortosa MC, Sol J, Ruiz-Sanjuan M, Fernandez M, de la Torre Cabrera C, Ramírez-Tortosa C, Granados-Principal S, et al: A plasma metabolomic signature discloses human breast cancer. Oncotarget 8: 19522-19533, 2017.

24. Pandey R, Caflisch L, Lodi A1, Brenner AJ and Tiziani S: Metabolomic signature of brain cancer. Mol Carcinog 56: 2355-2371, 2017.

25. Navas-Carrillo D, Rodriguez JM, Montoro-García S and Orenes-Piñero E: High-resolution proteomics and metabolomics in thyroid cancer: Deciphering novel biomarkers. Crit Rev Clin Lab Sci 54: 446-457, 2017.

26. Chen L, Yang X, Cui X, Jiang MM, Gui Y, Zhang YN and Luo XD: Adrenomedullin is a key protein mediating rotary cell culture system that induces the effects of simulated microgravity on human breast cancer Cells. Microgravity Sci Technol 27: 417-426, 2015.

27. Michaletti A, Gioia M, Tarantino U and Zolla L: Effects of microgravity on osteoblast mitochondria: A proteomic and metabolomics profile. Sci Rep 7: 15376, 2017.

28. Morabito C, Steimberg N, Mazzoleni G, Guarnieri S, Fanò-Illic G and Mariggiò MA: RCCS bioreactor-based modelled microgravity induces significant changes on in vitro 3D neuroglial cell cultures. Biomed Res Int 2015: 754283, 2015.

29. Longo N, Frigeni M and Pasquali M: Carnitine transport and fatty acid oxidation. Biochim Biophys Acta 1863: 2422-2435, 2016.

30. Pietsch J, Ma X, Wehland M, Aleshcheva G, Schwarzwälder A, Segerer J, Birlem M, Horn A, Bauer J, Infanger M and Grimm D: Spheroid formation of human thyroid cancer cells in an automated culturing system during the Shenzhou- 8 Space mission. Biomaterials 34: 7694-705, 2013.

31. Riwaldt S, Pietsch J, Sickmann A, Bauer J, Braun M, Segerer J, Schwarzwälder A, Aleshcheva G, Corydon TJ, Infanger M and Grimm D: Identification of proteins involved in inhibition of spheroid formation under microgravity. Proteomics 15: 2945-2952, 2015. 
32. Arun RP, Sivanesan D, Vidyasekar P and Verma RS PTEN/FOXO3/AKT pathway regulates cell death and mediates morphogenetic differentiation of Colorectal Cancer Cells under Simulated Microgravity. Sci Rep 7: 5952, 2017.

33. Kopp S, Sahana J, Islam T, Petersen AG, Bauer J, Corydon TJ, Schulz H, Saar K, Huebner N, Slumstrup L, et al: The role of $\mathrm{NF \kappa B}$ in spheroid formation of human breast cancer cells cultured on the random positioning machine. Sci Rep 8: 921, 2018.

34. Chen ZY, Guo S, Li BB, Jiang N, Li A, Yan HF, Yang HM, Zhou JL, Li CL and Cui Y: Effect of weightlessness on the 3D structure formation and physiologic function of human cancer cells. Biomed Res Int 2019: 4894083, 2019

35. Marín de Mas I, Aguilar E, Jayaraman A, Polat IH, Martín-Bernabé A, Bharat R, Foguet C, Milà E, Papp B, Centelles JJ and Cascante M: Cancer cell metabolism as new targets for novel designed therapies. Future Med Chem 6 : $1791-1810,2014$

36. Zhu M, Jin XW, Wu BY, Nie JL and Li YH: Effects of simulated weightlessness on cellular morphology and biological characteristics of cell lines SGC-7901 and HFE-145. Genet Mol Res 13. 6060-6069, 2014.

37. Espinosa-Jeffrey A, Nguyen K, Kumar S, Toshimasa O, Hirose R, Reue K, Vergnes L, Kinchen J and Vellis J: Simulated microgravity enhances oligodendrocyte mitochondrial function and lipid metabolism. J Neurosci Res 94: 1434-1450, 2016.

38. Akagi T and Kimoto T: Human cell line (HGC-27) derived from the metastatic lymph node of gastric cancer. Acta Med Okayama 30: 215-219, 1976

39. Kawakami H, Zaanan A and Sinicrope FA: Microsatellite instability testing and its role in the management of colorectal cancer Curr Treat Options Oncol 16: 30, 2015.

40. Zalba S and Ten Hagen TL: Cell membrane modulation as adjuvant in cancer therapy. Cancer Treat Rev 52: 48-57, 2017.

41. Kim HY, Lee KM, Kim SH, Kwon YJ, Chun YJ and Choi HK Comparative metabolic and lipidomic profiling of human breast cancer cells with different metastatic potentials. Oncotarget 7 : 67111-67128, 2016.

42. Elvas F, Stroobants S and Wyffels L: Phosphatidylethanolamine targeting for cell death imaging in early treatment response evaluation and disease diagnosis. Apoptosis 22: 971-987, 2017.

43. Iorio E, Ricci A, Bagnoli M, Pisanu ME, Castellano G, Di Vito M Venturini E, Glunde K, Bhujwalla ZM, Mezzanzanica D, et al: Activation of phosphatidylcholine cycle enzymes in human epithelial ovarian cancer cells. Cancer Res 70: 2126-2135, 2010.

44. Grimm D, Bauer J, Kossmehl P, Shakibaei M, Schöberger J, Pickenhahn H, Schulze-Tanzil G, Vetter R, Eilles C, Paul M and Cogoli A: Simulated microgravity alters differentiation and increases apoptosis in human follicular thyroid carcinoma cells. FASEB J 16: 604-606, 2002.

45. Kossmehl P, Shakibaei M, Cogoli A, Infanger M, Curcio F, Schönberger J, Eilles C, Bauer J, Pickenhahn H, Schulze-Tanzil G, et al: Weightlessness induced apoptosis in normal thyroid cells and papillary thyroid carcinoma cells via extrinsic and intrinsic pathways. Endocrinology 144: 4172-4179, 2003.

46. Masiello MG, Cucina A, Proietti S, Palombo A, Coluccia P, D'Anselmi F, Dinicola S, Pasqualato A, Morini V and Bizzarri M: Phenotypic switch induced by simulated microgravity on MDA-MB-231 breast cancer cells. Biomed Res Int 2014: 652434 2014.

47. Zhao J, Ma H, Wu L, Cao L, Yang Q, Dong H, Wang Z, Ma J and Li Z: The influence of simulated microgravity on proliferation and apoptosis in U251 glioma cells. In Vitro Cell Dev Biol Anim 53: 744-751, 2017.

48. Paulick MG and Bertozzi CR: The glycosylphosphatidylinositol anchor: A complex membrane-anchoring structure for protein. Biochemistry 47: 6991-7000, 2008.

49. Ferguson MA, Homans SW, Dwek RA and Rademacher TW: Glycosyl-phosphatidylinositol moiety that anchors Trypanosoma brucei variant surface glycoprotein to the membrane. Science 239 753-759, 1988

50. Ferguson MA: The structure, biosynthesis and functions of glycosylphosphatidylinositol anchors, and the contributions of trypanosome research. J Cell Sci 112: 2799-2809, 1999.

51. Tsai YH, Liu X and Seeberger PH: Chemical biology of glycosylphosphatidylinositol anchors. Angew Chem Int Ed Engl 51: 11438-11456, 2012.

52. Chang D, Xu H, Guo Y, Jiang X, Liu Y, Li K, Pan C, Yuan M, Wang J, Li T and Liu C: Simulated microgravity alters the metastatic potential of a human lung adenocarcinoma cell line. In Vitro Cell Dev Biol Anim 49: 170-177, 2019.
53. Qian A, Zhang W, Xie L, Weng Y, Yang P, Wang Z, Hu L, Xu HY, Tian ZC and Shang P: Simulated weightlessness alters biological characteristics of human breast cancer cell line MCF-7. Acta Astronautica 63: 947-958, 2008.

54. Peng W, Tan S, Xu Y, Wang L, Qiu D, Cheng C, Lin Y, Liu C, $\mathrm{Li} \mathrm{Z,} \mathrm{Li} \mathrm{Y,} \mathrm{et} \mathrm{al:} \mathrm{LC-MS/MS} \mathrm{metabolome} \mathrm{analysis} \mathrm{detects} \mathrm{the}$ changes in the lipid metabolic profiles of dMMR and pMMR cells. Oncol Rep 40: 1026-1034, 2018.

55. Toshima K, Nagafuku M, Okazaki T, Kobayashi $T$ and Inokuchi JI: Plasma membrane sphingomyelin modulates thymocyte development by inhibiting TCR-induced apoptosis. Int Immunol 31: 211-223, 2019.

56. Hogan PG: Sphingomyelin, ORAI1 channels, and cellular $\mathrm{Ca} 2+$ signaling. J Gen Physiol 146: 195-200, 2015.

57. Matanes F, Twal WO and Hammad SM: Sphingolipids as biomarkers of disease. Adv Exp Med Biol 1159: 109-138, 2019.

58. Kohama T, Olivera A, Edsall L, Nagiec MM, Dickson R and Spiegel S: Molecular cloning and functional characterization of murine sphingosine kinase. J Biol Chem 273: 23722-23728, 1998.

59. Li J, Gray BD, Pak KY and Ng CK: Targeting phosphatidylethanolamine and phosphatidylserine for imaging apoptosis in cancer. Nucl Med Biol 78: 23-30, 2019.

60. Andrieu-Abadie N and Levade T: Sphingomyelin hydrolysis during apoptosis. Biochim Biophys Acta 1585: 126-134, 2002.

61. van der Hoeven D, Cho KJ, Zhou Y, Ma X, Chen W, Naji A, Montufar-Solis D, Zuo Y, Kovar SE, Levental KR, et al: Sphingomyelin metabolism is a regulator of K-Ras function. Mol Cell Biol 38: pii: e00373-17, 2018.

62. Fernández-Medarde A and Santos E: Ras in cancer and developmental diseases. Genes Cancer 2: 344-358, 2011.

63. Cacev T, Radosević S, Spaventi R, Pavelić K and Kapitanović S: NF1 gene loss of heterozygosity and expression analysis in sporadic colon cancer. Gut 54: 1129-1135, 2005.

64. Dhomen N and Marais R: New insight into BRAF mutations in cancer. Curr Opin Genet Dev 17: 31-39, 2007

65. Khoukaz T: Administration of anti-EGFR therapy: A practical review. Semin Oncol Nurs 22: 20-27, 2006.

66. Baek MO, Ahn CB, Cho HJ, Choi JY, Son KH and Yoon MS: Simulated microgravity inhibits $\mathrm{C} 2 \mathrm{C} 12$ myogenesis via phospholipase D2-induced Akt/FOXO1 regulation. Sci Rep 9: 14910, 2019

67. Wang Z, Zhang F, He J, Wu P, Tay LWR, Cai M, Nian W, Weng Y, Qin L, Chang JT, et al: Binding of PLD2-generated phosphatidic acid to KIF5B promotes MT1-MMP surface trafficking and lung metastasis of mouse breast cancer cells. Dev Cell 43: 186-197, 2017.

68. Zeiller C, Mebarek S, Jaafar R, Pirola L, Lagarde M, Prigent AF and Némoz G: Phospholipase D2 regulates endothelial permeability through cytoskeleton reorganization and occludin downregulation. Biochim Biophys Acta 1793: 1236-1249, 2009.

69. Ngo Thai Bich V, Hongu T, Miura Y, Katagiri N, Ohbayashi N, Yamashita-Kanemaru Y, Shibuya A, Funakoshi Y and Kanaho Y: Physiological function of phospholipase D2 in anti-tumor immunity: Regulation of CD8+ T lymphocyte proliferation. Sci Rep 8: 6283,2018

70. Kandori S, Kojima T, Matsuoka T, Yoshino T, Sugiyama A, Nakamura E, Shimazui T, Funakoshi Y, Kanaho Y and Nishiyama H: Phospholipase D2 promotes disease progression of renal cell carcinoma through the induction of angiogenin. Cancer Sci 109: 1865-1875, 2018.

71. Guo L, Cui C, Zhang K, Wang J, Wang Y, Lu Y, Chen K, Yuan J, Xiao G, Tang B, et al: Kindlin-2 links mechano-environment to proline synthesis and tumor growth. Nat Commun 10: 845, 2019.

72. Phang JM, Donald SP, Pandhare J and Liu Y: The metabolism of proline, a stress substrate, modulates carcinogenic pathways. Amino Acids 35: 681-690, 2008.

73. Liu W, Wang X, Liu Z, Wang Y, Yin B, Yu P, Duan X, Liao Z, Chen Y, Liu C, et al: SGK1 inhibition induces autophagy-dependent apoptosis via the mTOR-Foxo3a pathway. Br J Cancer 117: 1139-1153, 2017.

74. Wallimann T, Tokarska-Schlattner M and Schlattner U: The creatine kinase system and pleiotropic effects of creatine. Amino Acids 40: 1271-1296, 2011.

75. Campos-Ferraz PL, Gualano B, das Neves W, Andrade IT, Hangai I, Pereira RT, Bezerra RN, Deminice R, Seelaender M and Lancha AH: Exploratory studies of the potential anti-cancer effects of creatine. Amino Acids 48: 1993-2001, 2016.

76. Martin KJ, Chen SF, Clark GM, Degen D, Wajima M, Von Hoff DD and Kaddurah-Daouk R: Evaluation of creatine analogs as a new class of anticancer agents using freshly explanted human tumor cells. J Natl Cancer Inst 86: 608-613, 1994. 
77. Miller EE, Evans AE and Cohn M: Inhibition of rate of tumor growth by creatine and cyclocreatine. Proc Natl Acad Sci USA 90: 3304-3308, 1993.

78. Hoppeler H and Fluck M: Plasticity of skeletal muscle mitochondria: Structure and function. Med Sci Sports Exerc 35: 95-104, 2003.

79. Adams SH, Hoppel CL, Lok KH, Zhao L, Wong SW, Minkler PE, Hwang DH, Newman JW and Garvey WT: Plasma acylcarnitine profiles suggest incomplete long-chain fatty acid beta-oxidation and altered tricarboxylic acid cycle activity in type 2 diabetic African-American women. J Nutr 139: 1073-1081, 2009.

80. Chen WW, Freinkman E, Wang T, Birsoy K and Sabatini DM: Absolute quantification of matrix metabolites reveals the dynamics of mitochondrial metabolism. Cell 166: 1324-1337, 2016.

81. Hutschenreuther A, Birkenmeier G, Bigl M, Krohn K and Birkemeyer C: Glycerophosphoglycerol, Beta-alanine, and pantothenic acid as metabolic companions of glycolytic activity and cell migration in breast cancer cell lines. Metabolites 3: 1084-1101, 2013

82. Leonardi R and Jackowski S: Biosynthesis of pantothenic acid and coenzyme A. EcoSal Plus 2, 2007.

83. Vurusaner B, Poli G and Basaga H: Tumor suppressor genes and ROS: Complex networks of interactions. Free Radic Biol Med 52: 7-18, 2012.

84. Gomes AR, Brosens JJ and Lam EW: Resist or die: FOXO transcription factors determine the cellular response to chemotherapy. Cell Cycle 7: 3133-3136, 2008.
85. Hou YQ, Yao Y, Bao YL, Song ZB, Yang C, Gao XL, Zhang WJ, Sun LG, Yu CL, Huang YX, et al: Juglanthraquinone C induces intracellular ROS increase and apoptosis by activating the Akt/Foxo signal pathway in HCC cells. Oxid Med Cell Longev 2016: 4941623, 2016.

86. Maiese K, Chong ZZ, Hou J and Shang YC: Erythropoietin and oxidative stress. Curr Neurovasc Res 5: 125-142, 2008.

87. Nakamura T and Sakamoto K: Forkhead transcription factor FOXO subfamily is essential for reactive oxygen species-induced apoptosis. Mol Cell Endocrinol 281: 47-55, 2008.

88. Barthélémy C, Henderson CE and Pettmann B: Foxo3a induces motoneuron death through the Fas pathway in cooperation with JNK. BMC Neurosci 5:48, 2004.

89. Maiese K, Chong ZZ, Li F and Shang YC: Erythropoietin: Elucidating new cellular targets that broaden therapeutic strategies. Prog Neurobiol 85: 194-213, 2008.

90. Nowak K, Killmer K, Gessner C and Lutz W: E2F-1 regulates expression of FOXO1 and FOXO3a. Biochim Biophys Acta 1769: 244-252, 2007.

91. Liu Y, Ao X, Ding W, Ponnusamy M, Wu W, Hao X, Yu W, Wang Y, Li P and Wang J: Critical role of FOXO3a in carcinogenesis. Mol Cancer 17: 104, 2018.

(i) () $(-)$ This work is licensed under a Creative Commons International (CC BY-NC-ND 4.0) License. 